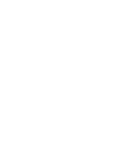

\section{REVIEWS Further}

Click here for quick links to Annual Reviews content online, including:

- Other articles in this volume

- Top cited articles

- Top downloaded articles

- Our comprehensive search

\title{
Systematic and Biogeographical Patterns in the Reproductive Biology of Scleractinian Corals
}

\author{
Andrew H. Baird, ${ }^{1}$ James R. Guest, ${ }^{2}$ \\ and Bette L. Willis ${ }^{1,3}$ \\ ${ }^{1}$ ARC Center of Excellence for Coral Reef Studies, James Cook University, Townsville, \\ Queensland 4811, Australia; email: andrew.baird@jcu.edu.au \\ ${ }^{2}$ Marine Biology Laboratory, Department of Biological Sciences, National University of \\ Singapore, Singapore 117543; email: james.guest@nus.edu.sg \\ ${ }^{3}$ School of Marine and Tropical Biology, James Cook University, Townsville, Queensland 4811, \\ Australia; email: bette.willis@jcu.edu.au
}

Annu. Rev. Ecol. Evol. Syst. 2009. 40:551-71

First published online as a Review in Advance on September 9, 2009

The Annual Review of Ecology, Evolution, and Systematics is online at ecolsys.annualreviews.org

This article's doi:

10.1146/annurev.ecolsys.110308.120220

Copyright (C) 2009 by Annual Reviews. All rights reserved

$1543-592 X / 09 / 1201-0551 \$ 20.00$

\section{Key Words}

breeding systems, coral reefs, climate change, dispersal, evolution, larval development, life histories, symbiosis, synchrony

\begin{abstract}
A limited diversity of character states for reproductive traits and a robust phylogeny make scleractinian corals an ideal model organism with which to explore the evolution of life-history traits. Here, we explore systematic and biogeographical patterns in the reproductive biology of the Scleractinia within the context of a new molecular phylogeny and using reproductive traits from nearly 400 species. Our analyses confirm that coral sexuality is highly conserved, and mode of larval development is relatively plastic. An overabundance of species with autotrophic larvae in the eastern Pacific and Atlantic is most likely the result of increased capacity for long-distance dispersal conferred by vertical transmission of symbiotic zooxanthellae. Spawning records from diverse biogeographical regions indicate that multispecies spawning occurs in all speciose coral assemblages. A new quantitative index of spawning synchrony shows peaks at mid-tropical latitudes in the IndoPacific, influenced in part by two spawning seasons in many species on equatorial reefs.
\end{abstract}




\section{INTRODUCTION}

Nearly two decades have passed since the last major review of reproduction in the Scleractinia (Harrison \& Wallace 1990, Richmond \& Hunter 1990). In this time, the number of coral species for which reproductive traits are known has doubled and the geographical extent of coral reproduction studies has increased dramatically, particularly in regions such as the Coral Triangle that were previously underrepresented. In addition, the molecular phylogenies of Romano \& Cairns (2000), Fukami et al. (2004,2008), and Kerr (2005) have resulted in a complete revision of the systematics of the order and provided a new, robust working hypothesis of scleractinian phylogeny. These recent advances enable the evolution of life-history traits in corals to be examined using the techniques of comparative biology for the first time. In this review, we begin by outlining various hypotheses that have been put forward to explain systematic patterns in reproductive traits and we test these hypotheses in the context of the new molecular phylogeny. Next, we examine geographical patterns in the relative abundance of reproductive traits to gain new insights about the biogeography of the Scleractinia. We then outline global patterns of coral spawning synchrony and discuss the environmental controls and evolutionary constraints driving synchronous spawning phenomena. Finally, we outline the potential effects of climate change on coral reproduction, particularly on the timing of spawning, and discuss how these changes may affect reef futures.

\section{SYSTEMATIC PATTERNS IN REPRODUCTIVE BIOLOGY OF SCLERACTINIAN CORALS}

Scleractinian corals are among the most extensively studied of marine modular organisms. Of the approximately 1400 extant species, about 800 or $60 \%$ are colonial (Cairns 1999). Modular, colonial organisms are unusual because the "organism" is comprised of many replicated, interdependent modules, each with its own birth and death rates, complicating analyses of life-history patterns. Modularity can potentially lead to a diverse array of sexual systems (Weiblen et al. 2000). However, unlike flowering plants (Barrett 1998) and some unitary animals (Francis 1992), there are essentially only two sexual systems in scleractinians. Colonies are either predominately out-crossing, simultaneous hermaphrodites, with each polyp having both male and female functions, or polyps within a colony express only one sex throughout their life; thus colonies are either male or female and species are gonochoric (that is, dioecious) [see Harrison \& Wallace 1990 for a review; see also Supplemental Appendix I. (Follow the Supplemental Material link from the Annual Reviews home page at http://www.annualreviews.org.)].

Most hermaphroditic corals are simultaneous, producing both eggs and sperm within one complete breeding cycle. Some corals, for example Stylophora pistillata (Rinkevich \& Loya 1979), are protandrous simultaneous hermaphrodites, that is, colonies display solely male function at small size but become simultaneous hermaphrodites once colonies exceed a species-specific characteristic size. Protandrous hermaphroditism is readily explained by models that predict delayed allocation to more energetically costly female function until larger sizes are attained (Charnov 1982). At least four solitary fungiid species are sequential protandrous hermaphrodites, that is, polyps display solely male function when small and solely female function when larger (KramarskyWinter \& Loya 1998, Loya \& Sakai 2008) in accord with sex-allocation theory (Charnov 1982). In addition, the fungiid Ctenactis echinata can change sex in both directions, possibly in response to energetic and/or environmental constraints (Loya \& Sakai 2008).

Mixed breeding systems are rare in scleractinian corals. In a few colonial species, some polyps are male and others female. Examples include Cladopsammia rolandi and Diploastrea helipora (Supplemental Appendix I). At least one scleractinian, Galaxea fascicularis, is pseudo-gynodioecious, 
that is, populations consist of female colonies that release eggs and male colonies that release sperm packaged with nonviable eggs, which potentially provide buoyancy for sperm (Harrison 1988). In addition, a low proportion of hermaphrodites is often found in otherwise gonochoric populations, including species in the families Agariciidae (Delvoye 1988, Glynn et al. 1996) and Poritidae (Glynn et al. 1994, Soong 1991); such species are described by Giese \& Pearse (1974) as stable gonochores. Although these are important exceptions, the vast majority of scleractinian species can be classified as either hermaphroditic or gonochoric.

Similarly, there are essentially only two modes of larval development in scleractinian corals (hereafter referred to as reproductive mode). Fertilization is either internal and the embryo develops within the polyp and is released as a motile planula larva (that is, brooding), or fertilization is external and the embryo develops in the water column (that is, broadcast spawning). Whereas surface brooding is common among octocorals (McFadden et al. 2001), it is rare within the Scleractinia; the only known exception is Pseudosiderastreidae tayamai, which releases eggs into an external mucus sac where they are fertilized (Supplemental Appendix I). In addition, some brooded larvae are produced asexually (Ayre \& Miller 2004, Cairns 1988, Stoddart 1983); however, the precise nature of this process is unknown. This ready classification of scleractinian reproductive traits into one of two character states makes them tractable organisms for studies of character evolution.

\section{Systematic Patterns in Scleractinian Reproductive Biology Based on Morphological Phylogenies}

Significant macroevolutionary patterns in reproductive characters have been noted in the order over the past two decades in relation to morphologically based systematic frameworks, some of which are contradictory. On the basis of anatomical and physiological simplicity, Fautin (2002) concluded that members of the phylum Cnidaria are evolutionarily plastic and therefore exhibit few patterns in reproductive traits. Within the Scleractinia, however, Harrison \& Wallace (1990) identified a "fundamental pattern in coral reproduction" noting that, with few exceptions, sexuality is constant within each species, genus, and family and therefore must have a strong systematic basis. In contrast, they found no systematic pattern in reproductive mode because most families and genera include species that spawn as well as species that brood. They concluded that mode of reproduction is a plastic trait and has evolved independently in many taxa, whereas sexuality is highly conserved and therefore likely to have evolved at a much slower rate. Many researchers have noted the overwhelming abundance of hermaphrodites in the order. On this basis, Szmant (1986) hypothesized that hermaphroditism was the ancestral condition in the Scleractinia. However, on the basis of differences in sperm morphology, Harrison (1990) concluded that gonochorism was the more primitive character state. Two decades of accumulated data, including a plethora of new information on reproductive traits and the recent molecular phylogeny, now allow these observations to be tested within a robust evolutionary framework.

\section{Systematic Patterns in Scleractinian Reproductive Traits in the Context of a Molecular Phylogeny}

Here, we analyze systematic trends in reproductive traits within the order Scleractinia in the context of the new molecular phylogeny of Fukami et al. (2008) and with an updated database of reproductive traits. The morphological phylogenies of Wells (1957) and more recently Veron et al. (1996) are now understood to contain few, if any, monophyletic family groups (Fukami et al. 2008, Huang et al. 2009). The updated database of reproductive traits (Supplemental Appendix I) contains records for nearly 400 species, over twice the number of species examined 

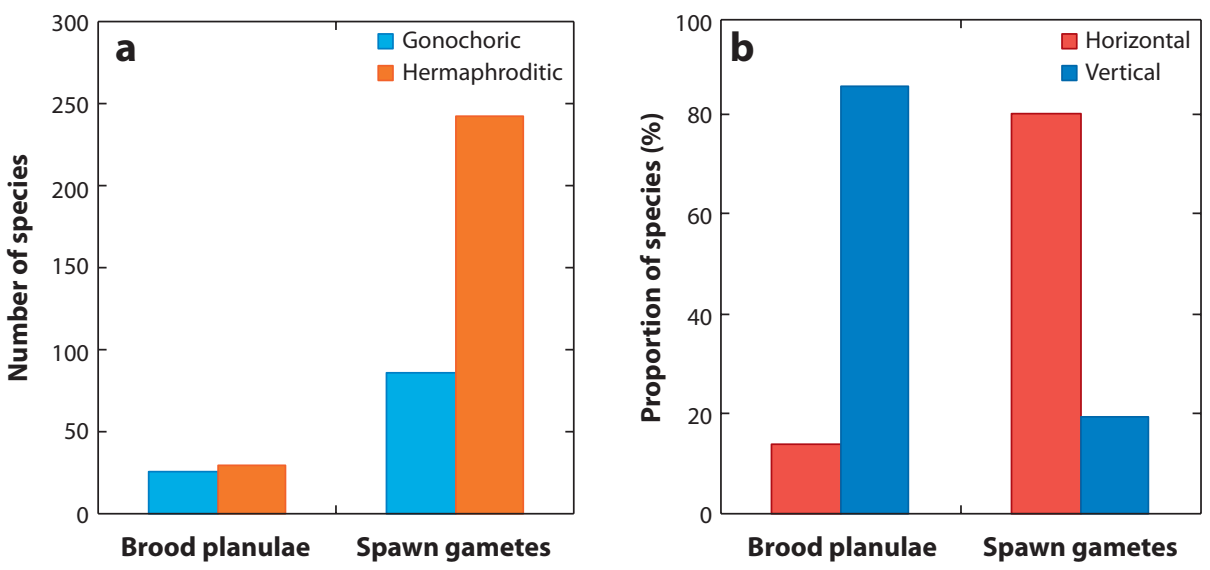

Figure 1

Systematic patterns in life-history traits of the Scleractinia. (a) The number of scleractinian species in each of four combinations of sexuality and mode of larval development. (b) The number of scleractinian species in each of four combinations of the reproductive traits, mode of larval development (brood planulae or spawn gametes), and mode of transmission of algal symbionts (vertical = zooxanthellae present in larvae or horizontal $=$ no zooxanthellae in larvae).

in the last analyses of systematic trends in the order (Carlon 1999, Harrison \& Wallace 1990). In agreement with earlier analyses, hermaphroditic spawning remains by far the most common combination of sexuality and mode of reproduction, with this pattern found in 242 or $63 \%$ of the species examined, while gonochoric brooding ( 26 species or $7 \%$ ) is the least common combination (Figure 1a). The consistency of sexuality within the monophyletic molecular clades is particularly striking (Table 1). Only 5 of the 31 clades contain species with both character states (Table 2), and many of these observations require further verification. For example, Isophyllia sinuosa is the only gonochoric mussid but this record dates back to the turn of the previous century (Duerden 1902) and warrants verification. Furthermore, the molecular markers for many of these species with atypical sexuality (e.g., all the caryophylliids) have yet to be examined, making their systematic affinities uncertain. Thus, the number of cases of species with sexuality atypical of the family/clade is reduced when the revised molecular phylogeny rather than the morphological phylogeny is used as the systematic framework.

Our analysis also confirms earlier suggestions that reproductive mode is more flexible than sexuality. According to the new molecular phylogeny, 13 of 31 clades contain both spawning and brooding species; however, even this trait appears relatively stable within clades. Only 13 of a total of 111 genera contain species that both brood and spawn (Table 3), one example arising as a result of a recent taxonomic revision of Acrhelia borrescens, which Veron (2000) has classified as Galaxea acrhelia. A further four of these examples are species in which individual colonies both brood and spawn (Heliofungia actiniformis, Goniastrea aspera, Oulastrea crispata, Pocillopora damicornis; Supplemental Appendix I). Clearly, reproductive traits are an excellent guide for systematic affinities among the Scleractinia.

In the first phylogenetic analysis of the evolution of character traits within the Scleractinia, Kerr and colleagues (A. Kerr, A. Baird, T. Hughes, submitted) found that transitions between sexuality occur about half as frequently as transitions between reproductive modes. Using a "supertree" phylogeny (Kerr 2005) of 242 species of scleractinian corals for which data on both sexuality and mode of reproduction were available, they also found that transitions from brooding to spawning 
Table 1 Summary of information on sexuality and reproductive mode for scleractinian corals grouped under the new taxonomy of Kerr (2005) and Fukami et al. (2008)

\begin{tabular}{|c|c|c|c|c|}
\hline \multirow[b]{2}{*}{ Family/clade } & \multicolumn{2}{|c|}{ Sexuality } & \multicolumn{2}{|c|}{ Reproductive mode } \\
\hline & Gonochoristic & Hermaphroditic & Brood planulae & Spawn gametes \\
\hline \multicolumn{5}{|l|}{ Complex } \\
\hline Acroporidae & & 144 & 6 & 139 \\
\hline Agariciidae & 11 & & 4 & 9 \\
\hline \multicolumn{5}{|l|}{ Anthemiphylliidae } \\
\hline Astrocoeniidae & 2 & & & 2 \\
\hline Bathycola & 8 & & 5 & 2 \\
\hline Dendrophylliidae & 12 & 2 & 12 & 7 \\
\hline Euphyllidae & 5 & 2 & 2 & 6 \\
\hline Fungiacyathidae & 1 & & & 1 \\
\hline \multicolumn{5}{|l|}{ Gardineriidae } \\
\hline New Clade 5 & 3 & & & 3 \\
\hline Poritidae & 23 & & 10 & 18 \\
\hline Siderastreidae & 3 & & 2 & 2 \\
\hline Complex total & 68 & 148 & 41 & 189 \\
\hline \multicolumn{5}{|l|}{ Robust } \\
\hline Caryophylliidae & 7 & 4 & 1 & 9 \\
\hline Faviidae & 1 & 57 & 2 & 56 \\
\hline Faviidae plus Merulinidae & & 4 & & 4 \\
\hline Faviidae plus Pectiniidae & & 8 & & 8 \\
\hline Faviidae plus Trachyphyllidae & & 1 & & 1 \\
\hline Fungiidae & 28 & & 2 & 24 \\
\hline \multicolumn{5}{|l|}{ Guyniidae } \\
\hline Meandrinidae & 5 & & & 5 \\
\hline Merulinidae & & 1 & & 1 \\
\hline Mussidae & 1 & 14 & 6 & 9 \\
\hline New Clade 1 & & 14 & & 14 \\
\hline New Clade 2 & 1 & & & 1 \\
\hline New Clade 3 & 1 & & & 1 \\
\hline \multicolumn{5}{|l|}{ New Clade 4} \\
\hline New Clade 4 plus Fungiidae & & 2 & 1 & 1 \\
\hline \multicolumn{5}{|l|}{ New Clade 5} \\
\hline New Clade 6 & & 1 & & 1 \\
\hline \multicolumn{5}{|l|}{ New Clade 7} \\
\hline \multicolumn{5}{|l|}{ New Clade 8} \\
\hline \multicolumn{5}{|l|}{ New Clade 9} \\
\hline New Clade XIV & 2 & & & 2 \\
\hline Oculinidae & 5 & & & 3 \\
\hline \multicolumn{5}{|l|}{ Pectiniidae } \\
\hline Pocilloporidae & & 17 & 11 & 6 \\
\hline Rhizangiidae & 3 & & & 3 \\
\hline Robust Total & 54 & 123 & 23 & 149 \\
\hline Grand Total & 122 & 271 & 64 & 338 \\
\hline
\end{tabular}


Table 2 Species with sexuality atypical of the revised family/clade of Fukami et al. (2008)

\begin{tabular}{l|l|l|l|l}
\hline Major division & Family/clade & \multicolumn{1}{|c|}{ Genus } & \multicolumn{1}{c|}{ Species } & Atypical sexuality \\
\hline Complex & Dendrophylliidae & Astroides & calycularis & hermaphroditic \\
\hline & & Balanophyllia & europaea & hermaphroditic \\
\hline & Euphylliidae & Euphyllia & glabrescens & hermaphroditic \\
\hline & & Galaxea & acrhelia & hermaphroditic \\
\hline & & Galaxea & astreata & hermaphroditic \\
\hline & Poritidae & Porites & astroides & hermaphroditic \\
\hline & & Porites & lichen & hermaphroditic \\
\hline & Caryophyllidae & Caryophyllia & ambrosia ambrosia & hermaphroditic \\
\hline & & Caryophyllia & cornuformis & hermaphroditic \\
\hline & & Caryophyllia & seguenzae & hermaphroditic \\
\hline & & Hoplangia & durotrix & hermaphroditic \\
\hline & Mussidae & Isophyllia & sinuosa & gonochoric \\
\hline
\end{tabular}

Table 3 Genera with mixed modes of reproduction (only 13 of 110 genera for which record exists)

\begin{tabular}{l|c|c}
\hline Genus & Brood planulae & $\begin{array}{c}\text { Spawn } \\
\text { gametes }\end{array}$ \\
\hline Alveopora & 2 & 3 \\
\hline Flabellum & 3 & 2 \\
\hline Euphyllia & 1 & 3 \\
\hline Galaxea & 1 & 2 \\
\hline Porites & 10 & 10 \\
\hline Siderastrea & 2 & 1 \\
\hline Caryophyllia $_{\text {Cyphastrea }}$ & 1 & 4 \\
\hline Goniastrea $^{\mathrm{a}}$ & 1 & 3 \\
\hline Heliofungia $^{\mathrm{a}}$ & 1 & 7 \\
\hline Leptastrea $^{\text {Oulastrea }}$ & 1 & 3 \\
\hline Pocillopora $^{\mathrm{a}}$ & 1 & 1 \\
\hline
\end{tabular}

aAll have colonies that both brood and spawn.

outnumbered reverse transitions by more than two to one. The analysis overwhelmingly supported gonochorism as the ancestral sexual state, but was ambiguous as to reproductive mode (Figure 2). These results are consistent with gonochorism being the prevalent and presumably ancestral state in the rest of Anthozoa (Daly et al. 2003).

Another prominent systematic pattern, most recently noted by Diekmann et al. (2002), is the strong association between mode of larval development and the mode of transmission of Symbiodinium, the dinoflagellate endosymbiont of corals commonly known as zooxanthellae (Figure $\mathbf{1} \boldsymbol{b}$ ). In all symbiotic organisms, offspring acquire symbionts in one of two ways: either inherited directly from parents in the oocytes (vertical transmission), or acquired anew in each generation (horizontal transmission). Approximately $90 \%$ of brooding scleractinian species ( $n=36$ species) have zooxanthellae in their planulae (Figure $\mathbf{1} \boldsymbol{b}$ ). One of the aberrant species, Madracis mirabilis, comes 
from a genus in which many species are azooxanthellate or facultatively zooxanthellate (although this species is regarded as zooxanthellate), leaving only three species, all isoporans, that brood and lack zooxanthellae (Supplemental Appendix I). In contrast, only 25\% of spawning species have zooxanthellae in their eggs, and these species come from only 4 of the 85 genera of zooxanthellate scleractinians: Montipora, Anacropora, Pocillopora, and Porites. What has driven the evolution of this pattern? Yakovleva et al. (2009) suggested that vertical transmission may be precluded in spawning species because of physiological constraints associated with extended obligate periods of larval development on the ocean surface. Higher rates of enzymatic antioxidant activity, high levels of cellular damage, and lower survivorship of Acropora intermedia larvae when inoculated with Symbiodinium and exposed to conditions prevalent on the ocean surface in comparison to larvae that lacked symbionts (Yakovleva et al. 2009) provide corroborative evidence for this hypothesis.

\section{BIOGEOGRAPHICAL AND EVOLUTIONARY PATTERNS IN THE RELATIVE ABUNDANCE OF REPRODUCTIVE TRAITS}

Distinct differences in the relative abundance of reproductive traits, in particular, sexuality and reproductive mode have been recognized among reef regions and through evolutionary time. For example, Harrison \& Wallace (1990) noted that sexual systems differed among Atlantic and Indo-Pacific faunas within the genera Porites (gonochoric in the Indo-Pacific, hermaphroditic in the Atlantic) and Montastrea (hermaphroditic in the Indo-Pacific, one gonochoric species in the Atlantic), a pattern that they attributed to evolutionary divergence since separation of the faunas. Szmant (1986) first noted that brooding corals were relatively more abundant in the Atlantic when compared to the Indo-Pacific, a feature she attributed to differences in selective pressures between the two regions over evolutionary time. In particular, Szmant (1986) hypothesized that brooding is the optimal strategy for high recruitment under conditions of low larval survivorship potentially caused by environmental perturbations in the Atlantic associated with tectonic events and changes in ocean circulation since the Oligocene. Similarly, Edinger \& Risk (1995) suggested that fewer brooders had gone extinct during the Oligocene/Miocene extinction event, a result that they attributed to the greater capacity of brooded larvae to recruit and survive in marginal conditions such as cool and turbid water associated with increasing upwelling in the Atlantic in the Oligocene. They estimated that of 37 genera for which they inferred reproductive mode, $73 \%$ of brooding genera survived the extinction, compared to $29 \%$ of broadcasting genera (Edinger \& Risk 1995). In contrast, Johnson et al. (1995) concluded that neither sexuality nor reproductive mode was associated with extinction risk at the species level. Instead, they found that species characterized by large colony size went extinct less frequently and originated more frequently than species with smaller colony size (Johnson et al. 1995). How well do these ideas stand up in light of the twofold increase in records of reproductive traits and a more extensive fossil record?

An examination of the relative abundance of species in the four combinations of sex and mode reveals some prominent biogeographical patterns (Figure 3a). Brooding corals are relatively more abundant in the Atlantic, where they make up nearly 50\% of the species compared to less than $20 \%$ in the Indo-Pacific (Figure 3a), confirming and accentuating the pattern first noted by Szmant (1986). Indeed, coral species are much more evenly spread among the four reproductive states in the Atlantic, whereas in the Indo-Pacific, hermaphroditic spawners are overwhelmingly more abundant (70\%) (Figure 3a). Is this pattern in the Atlantic driven by lower rates of extinction of brooders as suggested by Edinger \& Risk (1995). Using more recently compiled generic records of fossil occurrence and a more complete data set of coral reproductive traits, Baird and colleagues (A. Baird, A. Kerr, M. Kosnik, submitted) demonstrated that there was, in fact, no association between either sexuality or mode of reproduction and extinction in the Oligocene. They concluded, 
a

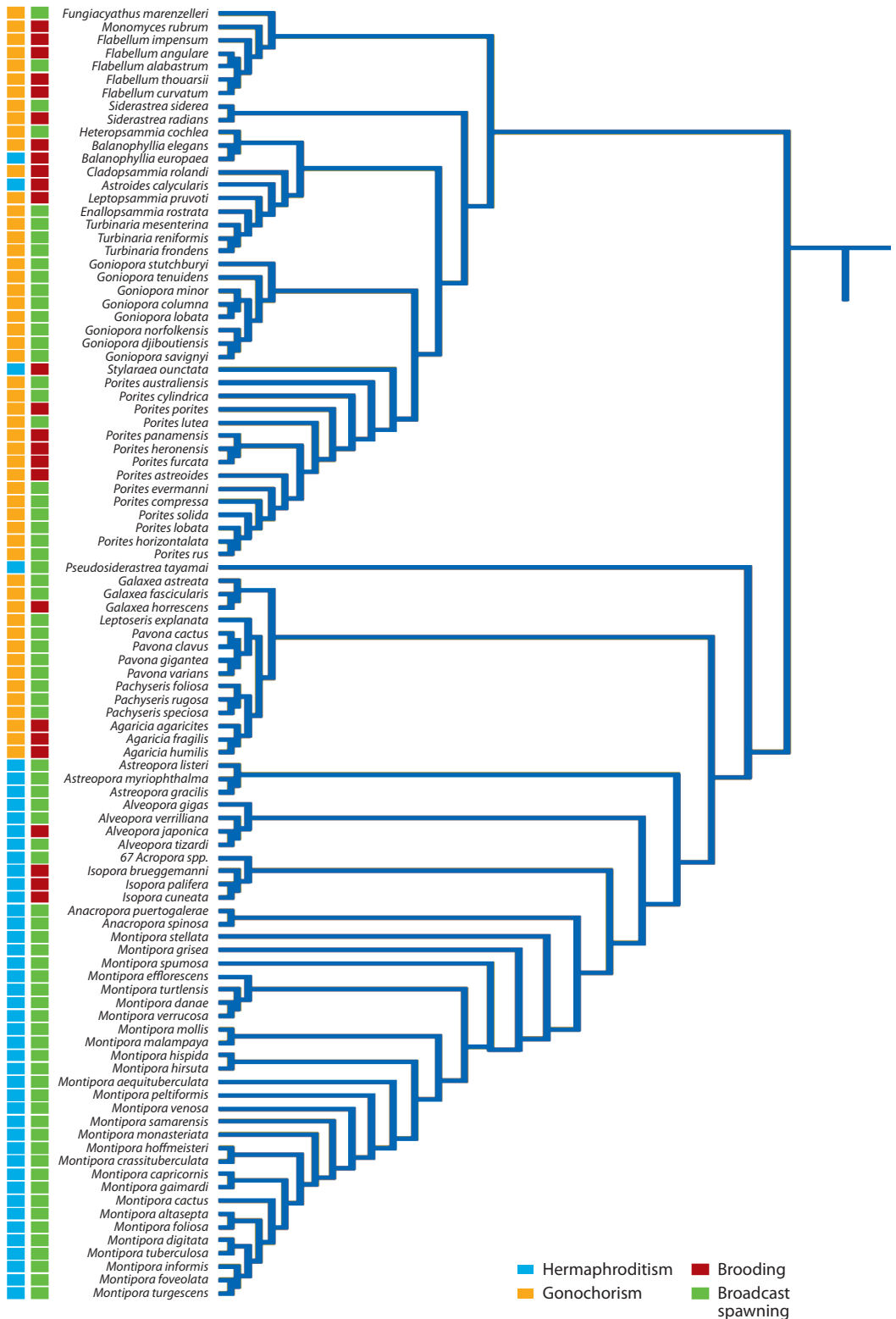

*Erratum

Figure 2

$(a, b)$ Sexual system (light blue, hermaphroditic; orange, gonochoric) and reproductive mode (red, brood planulae; green, spawn gametes) in 289 species of scleractinian corals mapped onto the supertree phylogeny of $\operatorname{Kerr}(2005)$.

*This PDF amended on (24 Feb. 2010): See explanation at http://arjournals.annualreviews.org/errata/ecolsys 


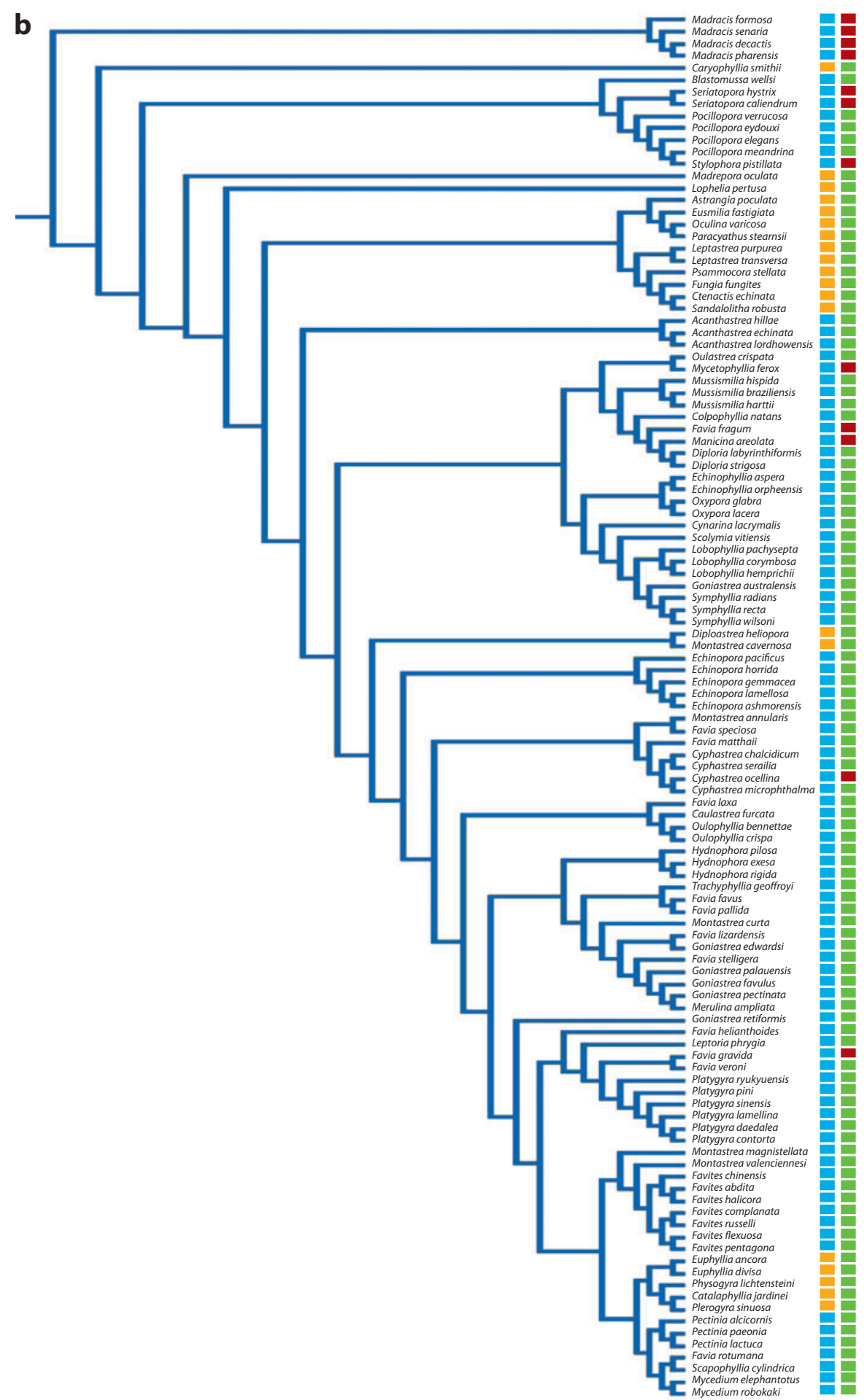

Figure 2 

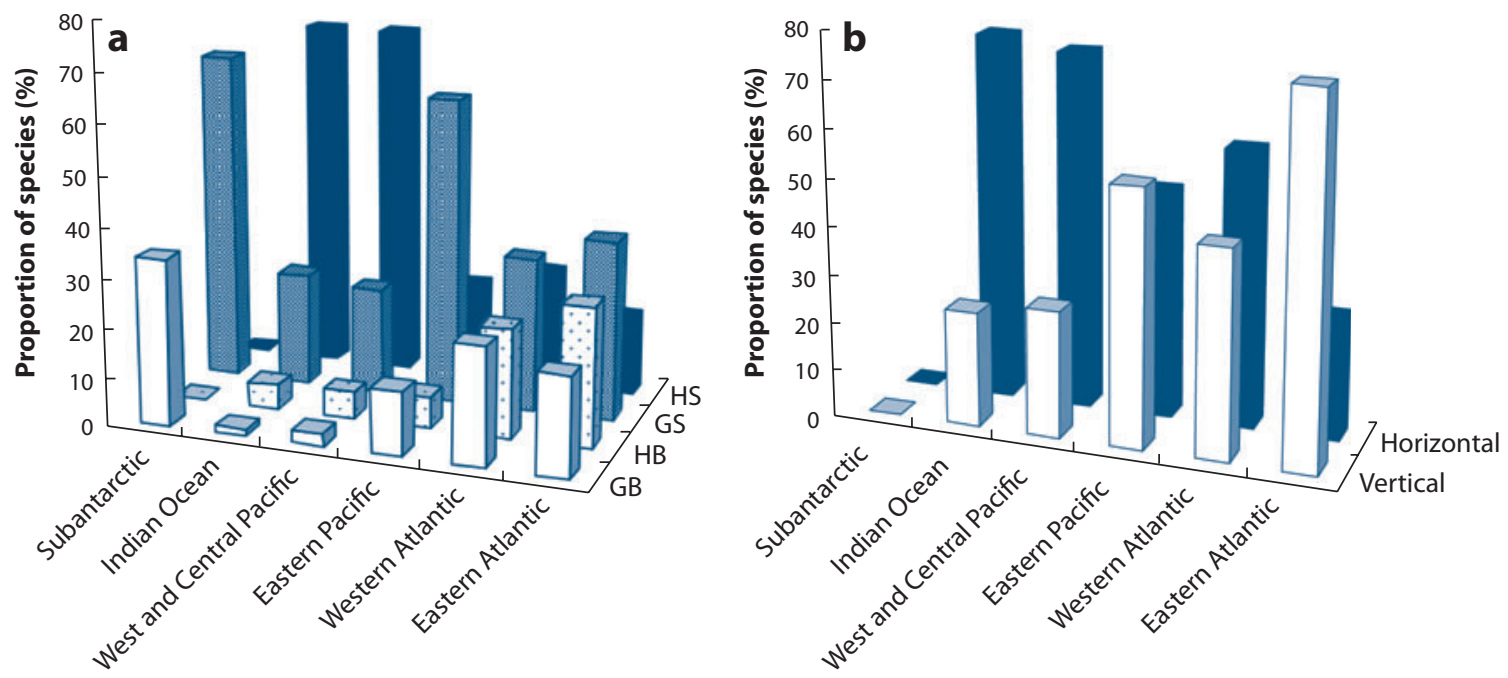

Figure 3

Biogeographical patterns in the relative abundance of life-history traits in the Scleractinia in six regional faunas. (a) The proportions of scleractinian species in each of four combinations of sexuality and mode of larval development. (b) The proportion of zooxanthellate scleractinian coral species with vertical (zooxanthellate larvae) and horizontal (azooxanthellate larvae) transmission of symbionts.

rather, that the overabundance of brooders in the Atlantic preceded the Oligocene extinction and hypothesized that patterns were the product of greater dispersal abilities of brooders across the eastern Pacific divide, which isolated the Atlantic from the Indo-Pacific many epochs before the Oligocene extinction (Veron 1995). In examining extinction risk in the Atlantic, Edinger \& Risk (1995) explicitly rejected this dispersal hypothesis. However, some of their reasoning was based on an inappropriate distinction between lecithotrophic and planktotrophic larvae. They defined brooded larvae as lecithotrophic, reasoning that because the larvae are typically larger and almost always inherit symbionts vertically, they could spend long periods in the water column nourished by maternal provisionings. They contrasted this with the larvae of broadcast spawning species-which are smaller and typically lack symbionts—and reasoned that if these larvae were to spend time in the water column, they would need to feed. Consequently, they defined the larvae of broadcast spawners as planktotrophic. However, the term planktotrophic is best reserved for larvae that have to feed to complete development within the water column (Pechenik 1990). Clearly, this is not true for any scleractinian larvae, all of which can settle without nutrition derived from the water column (Morse et al. 1996). Furthermore, there is little evidence to suggest that any coral larvae actually feed (Graham et al. 2008). The correct distinction is between autotrophic larvae, that is, larvae that inherit symbionts vertically and can therefore supplement maternal provisioning with energy sources provided by their photosynthetic symbionts, versus lecithotrophic larvae, that is, those that cannot supplement their maternal energy reserves (Richmond 1988). Given this distinction, autotrophic larvae include all larvae of brooding species, with the exception of the isoporans, plus larvae of spawning species from the genera Montipora, Porites, Pocillopora, and Anacropora (Supplemental Appendix I). The overabundance of species with autotrophic larvae in the eastern Pacific (Figure $3 \boldsymbol{b}$ ) also suggests that this characteristic allowed them to travel large distances in the water column to colonize these reefs following the extinction of corals after the closing of the Isthmus of Panama. 
The differences in sexuality between Atlantic and Indo-Pacific species of Porites, Montastrea, and Agariciidae highlighted by Harrison \& Wallace (1990), and more recently, Scolymia (hermaphroditic in the Indo-Pacific and gonochoric in the Atlantic), are not supported by analyses of our extended records. The examples given by Harrison \& Wallace (1990) are now understood to be systematic artifacts or based on species atypical of the genera. For example, all but one species of Porites in the Atlantic are now regarded as gonochores, or stable gonochores, and hermaphroditic Porites have also been described in the Indo-Pacific (Supplemental Appendix I). Similarly, more recent work on agariciids suggests both Atlantic and Indo-Pacific species are best described as stable gonochores (Supplemental Appendix I). The other genera previously thought to have mixed sexuality among oceans are now recognized as being polyphyletic, with the gonochoric species of Montastrea and Scolymia now placed in different clades than their hermaphroditic congeneric species (Fukami et al. 2008).

Other prominent patterns include the complete absence of hermaphrodites in the Subantarctic and a very high abundance of gonochoric spawners in the eastern Pacific (Figure $3 \boldsymbol{b}$ ). This pattern, first noted by Glynn \& Ault (2000), contrasts sharply with the pattern identified by Edinger \& Risk (1995), who stated that the eastern Pacific was dominated by brooding genera. Glynn \& Ault (2000) also noted the other reproductive trait that predominates in the eastern Pacific fauna-the overabundance of species that inherit zooxanthellae vertically (Figure $3 \boldsymbol{b}$ ). As discussed above, this property is almost certainly related to greater potential for long-distance dispersal of species with autotrophic larvae, enabling them to survive extended planktonic periods required to reach eastern Pacific reefs.

\section{BIOGEOGRAPHICAL PATTERNS IN CORAL SPAWNING SYNCHRONY}

\section{Controls on the Timing of Reproduction}

Control of reproductive timing is complex and may involve an array of environmental signals that must be translated by the organism. These signals provide direction for a temporal series of physiological events that lead to gamete maturation and eventual spawning. Establishing which factors control reproductive timing is problematic because causation cannot be established by observations or correlations alone, and experiments that manipulate environmental factors such as light and temperature over the period of a coral gametogenic cycle are technically challenging (Hunter 1988).

A wide range of environmental factors may play a role in reproductive timing and these may act at both a proximate and an ultimate level (Olive et al. 2000, Oliver et al. 1988). The most common hypothesis for corals states that environmental cues work at progressively finer scales to regulate (a) the time of year, (b) night of spawning, and (c) the time of spawning (Babcock et al. 1986). Traditionally, sea surface temperature (SST) has been considered the major seasonal cue partly because of the important influence that temperature exerts on physiological processes and partly because many examples of broadcast spawning occur as waters are warming or close to the annual maxima in many locations (Harrison \& Wallace 1990). Perhaps the strongest evidence for a role of temperature is the timing of the inshore versus offshore spawning of corals in the central Great Barrier Reef (GBR) (Willis et al. 1985), where species on inshore reefs spawn a month earlier than colonies of the same species at mid- and outer-shelf reefs, and these spawning peaks are correlated with rising sea surface temperatures that begin a month earlier closer to the mainland (Babcock et al. 1986, Willis et al. 1985). Given that these reefs are at the same latitude and separated by a maximum of $60 \mathrm{~km}$, it is unlikely that other potential causal environmental variables, such as insolation, day length, or time of sunrise, vary between these locations. 


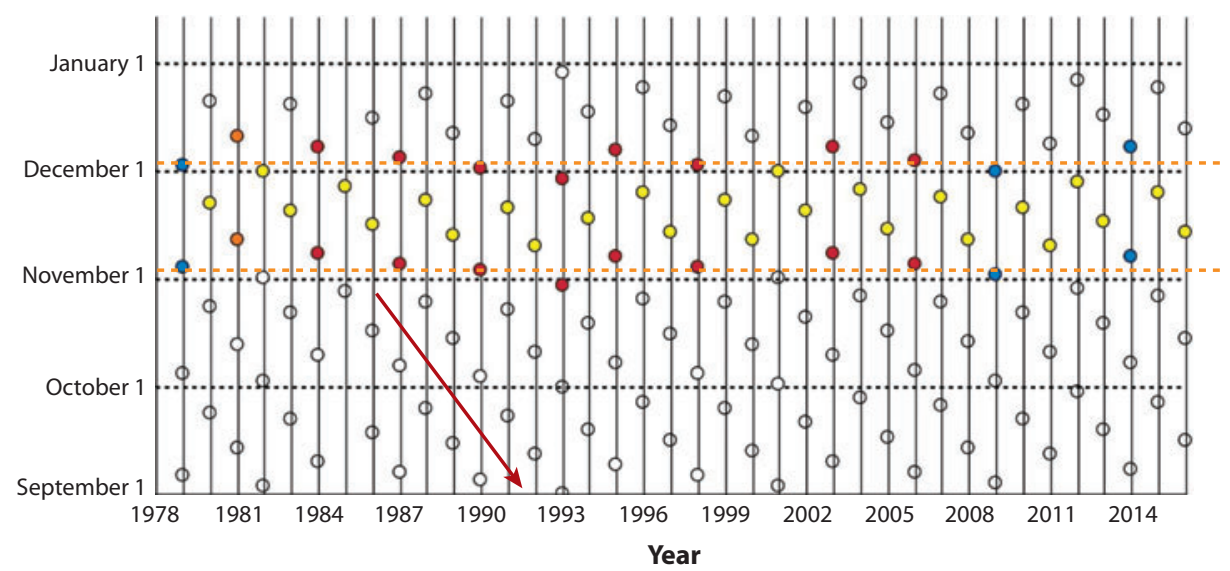

Figure 4

Long-term patterns in the timing of single versus split spawning years for an assemblage of corals at Orpheus Island, central Great Barrier Reef. Data points indicate the position of September to January full moons each year. Yellow full moons indicate a mass spawning year (spawning over 1 month only); red, a split spawning year (spawning over 2 months); and blue, a predicted split spawning year. Orange lines enclose an environmental window within which mass spawning years are maintained by inserting a split spawning year every 2-3 years to realign spawning rhythms. Red arrow indicates timing of spawning if species spawned every 12 lunar months, in the absence of realignment cycles. Figure from A. Pharaoh \& B. Willis (submitted).

Nonetheless, inconsistencies in the relationship between SST and spawning season are evident (Babcock et al. 1994, Mendes \& Woodley 2002, Penland et al. 2004). For example, corals on the east and west coasts of Australia spawn predominantly in different seasons despite similar annual SST regimes (Simpson 1985). In western Atlantic broadcast spawning corals, the rate of change in SST is a poor predictor of spawning time; rather, the average temperature at the time of spawning is important and most corals spawn when SSTs are between $28^{\circ} \mathrm{C}$ and $30^{\circ} \mathrm{C}$. Conversely, the rate of change of insolation is a good predictor of spawning, whereas average insolation at the time of spawning is not (van Woesik et al. 2006).

Environmental cues that influence the day of the month and hour of spawning are better understood. Lunar control of the night of spawning is strongly supported by experimental manipulative studies (Hunter 1988) and by long-term observations of the timing of spawning, which demonstrate that spawning patterns consistently track lunar patterns (Figure 4). Long-term observations also suggest that lunar and seasonal cues interact to maintain spawning on the GBR within a seasonal environmental window that is presumably favorable for reproductive success (A. Pharaoh \& B. Willis, submitted). Hence, split spawning years, when coral populations divide spawning over two consecutive months (Willis et al. 1985), can be explained by annual reproductive rhythms that are variable with respect to the number of lunar months (that is, 12 or 13) elapsing between spawning in successive years, thereby maintaining consistency in breeding season (Figure 4) (A. Pharaoh \& B. Willis, submitted). In Pocillopora damicornis, the lunar rhythm of planulae release is entrained (that is, the lunar cycle maintains the accuracy of an internal clock) (Jokiel et al. 1985). Furthermore, corals can detect low levels of lunar irradiance (Gorbunov \& Falkowski 2002) and possess blue light-sensing proteins that maintain circadian rhythms in insects and vertebrates (Levy et al. 2007). For broadcast spawning corals, onset of darkness is typically the final cue that determines the hour of spawning (Babcock et al. 1986, Hunter 1988, Levitan et al. 2004); however, some species spawn during daylight hours (Kinzie 1993, Plathong et al. 2006). 


\section{Multispecific Synchronous Spawning}

Most scleractinian corals broadcast spawn (see Figure 1), producing lipid-rich, positively buoyant, lecithotrophic larvae. Because oogenic cycles in broadcast spawning species typically range from 6 to 14 months (Harrison \& Wallace 1990), each colony usually spawns only once per year on a seasonal cycle (but see Stobart et al. 1993, Mangubhai \& Harrison 2008b for a few exceptions). In light of restricted mating opportunities each year, as a consequence of evolutionary constraints imposed by the length of oogenetic cycles, spawning synchrony is likely to be highly adaptive in broadcasting species. Furthermore, fertilization success is greatly diminished in corals when small numbers of colonies spawn because of rapid gamete dilution (Oliver \& Babcock 1992, Levitan et al. 2004). Thus, many broadcast spawning corals spawn at predictable times each year (Willis et al. 1985), and individuals can be remarkably punctual. For example, colonies of Colpobyllia natans spawn within two minutes of the time at which they spawned the previous year, whereas Diploria strigosa, the least punctual species in a Texas Flower Garden assemblage, spawns within a time window of 1.5 hours (Vize 2006).

In many coral assemblages, spawning is synchronized not only among colonies within a population, but also among numerous species within an assemblage. During the annual "mass spawn" on the GBR (Harrison et al. 1984), up to 30 species release gametes within hours on a single reef (Willis et al. 1985) and over 130 species spawn in the weeks following the full moon in October and/or November (Willis et al. 1985, Harrison \& Wallace 1990). Multispecific spawning has since been recorded on many reefs in a variety of regions (Supplemental Appendix II). In contrast, there is no apparent overlap in spawning period for species within coral assemblages in some reef regions. For example, ecologically dominant species at Eilat in the northern Red Sea spawn in different seasons, months, and lunar phase (Shlesinger \& Loya 1985). Temporal reproductive isolation is also the pattern in parts of the central Pacific, Hawaii, and the eastern Pacific (Glynn \& Ault 2000, Richmond \& Hunter 1990, but see Kenyon 2008). In combination, patterns emerging from early studies suggested that "mass spawning," defined by Willis et al. (1985) as "the synchronous release of gametes by many species of corals, in one evening between dusk and midnight," was restricted to geographic regions with appropriate proximate cues. In particular, Oliver et al. (1988) hypothesized that mass spawning would only occur in regions where large fluctuations in environmental variables provide the necessary cues by which corals can synchronize spawning (Harrison \& Wallace 1990). Lack of precision in the definition of what constitutes mass spawning, however, has led to controversy over where and when it occurs. Harrison \& Booth (2007) suggest "'mass spawning' is distinguished from other lesser multispecific spawning patterns by its much larger ecological scale" and Mangubhai \& Harrison (2008a) argue that the term should be "restricted to describing these (GBR) extreme synchronous multispecific spawning events, rather than including all multispecific spawning." In the absence of an ecological justifiable guide as to where to draw the line between mass and multispecies spawning events and given that a primary objective of these studies is to identify drivers of spawning synchrony among coral species, an alternative quantitative approach may constitute a more productive way of addressing the question.

Two hypotheses underpin the mass spawning paradigm: (a) There is high spawning synchrony within coral populations over a wide geographic scale, and (b) spawning synchrony is greater in areas with large fluctuations in environmental variables. Below, we re-examine these hypotheses in the light of the numerous studies that have emerged since these ideas were originally formulated, in particular a wealth of novel data from regions, such as the central Indo-Pacific, that were previously underrepresented. We next formulate a quantitative index of spawning synchrony at both the population and assemblage scale in order to test the hypothesis that spawning synchrony is positively correlated with variation in environmental variables. 
Studies of reproductive synchrony within coral populations over broad spatial scales on the GBR demonstrate that, although some species spawn with remarkable synchrony, many species have extended breeding seasons. In three regions spanning the length of the GBR, most Acropora populations sampled in the week before the mass spawning period had a proportion of colonies in each of three reproductive conditions (mature, immature, and empty), indicating that spawning in these populations extended over at least two months (Baird et al. 2002). Similarly, the proportion of mature colonies of three species of Acropora varied dramatically among six regions on the GBR and among years, indicating major regional and annual differences in within-population reproductive synchrony (Hughes et al. 2000). Furthermore, in a 3-year study of spawning times in 12 morphospecies of the Acropora bumilis group, a second substantial spawning event occurred three months after an initial spawn in November, and 11 of the 12 taxa spawned in both events (Wolstenholme 2004). In addition, the first study to claim broad synchrony in spawning among coral assemblages on the GBR actually indicates spawning was split between November and December on at least 5 of the 12 reefs evaluated, and the number of empty colonies on many reefs suggests that these colonies were breeding at other times of the year (table 1 in Oliver et al. 1988, p. 805). Similarly, on the northwest coast of Australia, populations of at least four species of Acropora spawn in both autumn and spring (Rosser \& Baird 2009). A study of temporal patterns of broadcast spawning for 22 species of Acropora in the central GBR showed that spawning was synchronous within populations and between species for more than $75 \%$ of species, but the remaining $25 \%$ either had extended breeding seasons that encompassed the main mass spawning period, or were temporally isolated (A. Pharaoh \& B. Willis, submitted). As concluded by A. Pharaoh \& B. Willis (submitted), multispecies spawning patterns span a continuum from synchrony to asynchrony on the GBR, despite the presence of both substantial tidal signals and annual fluctuations in temperature and light.

Over the past two decades, multispecies spawning events have been described from 23 locations globally (Supplemental Appendix II). In addition, coral reproduction in most regions investigated is highly seasonal, with the vast majority of reproductive activity concentrated in two to three months, even in equatorial locations that were previously considered to lack seasons (e.g., Kenya: Mangubhai \& Harrison 2008a; Singapore: Guest et al. 2005a; and see Supplemental Appendix II) and in regions where breeding periods have previously been described as not seasonal (e.g., the Red Sea; Supplemental Appendix II). The ubiquitousness of coral multispecies spawning is not surprising given the potential for closely related species to respond similarly to local environmental cues (Oliver et al. 1988). Thus, it seems inevitable that multispecies spawning will occur in any diverse assemblages of broadcast spawning corals (Guest et al. 2005b). Earlier studies comparing regional patterns in spawning synchrony hypothesized that differing ranges in environmental variables underlie variation in spawning patterns (Oliver et al. 1988, Richmond \& Hunter 1990). More recent studies suggest that even relatively small changes in environmental variables might be sufficient to act as cues. Indeed, the rate of change is likely to be just as important as absolute changes in environmental variables (van Woesik et al. 2006).

\section{A Quantitative Definition of Spawning Synchrony}

Much of the recent confusion in the literature in relation to geographic patterns in mass spawning is caused by the lack of a quantitative definition of spawning synchrony (Baird \& Guest 2009). Reproductive synchrony can occur at several levels, e.g., individual (intracolony synchrony), species (population synchrony), and coral assemblage (multispecific synchronous spawning or "mass spawning"). In the strictest sense, synchrony is defined as spawning within a time window that enables successful cross fertilization. However, to test for proximate cues that coordinate spawning season, 
a definition of synchrony on the scale of months is appropriate. Examining seasonality offers the most promise because data on gamete maturity during any month can be collected relatively easily by observing oocyte pigmentation in broken sections in situ (Harrison et al. 1984, Baird et al. 2002).

Seasonality in breeding can be considered to have two essential components: (a) the length of the spawning season (defined here in months) and $(b)$ the proportion of the population that spawns in any one month. These components can be captured relatively easily using a seasonality index (SI). For example, a modified version of Simpson's diversity index can be adopted by replacing "species" with months and "number of individuals per species" with the proportion of a population spawning in any month, calculated as follows:

$$
S I=\frac{n 1(n 1-1)}{N(N-1)}+\frac{n 2(n 2-1)}{N(N-1)}+\frac{n 3(n 3-1)}{N(N-1)} \ldots,
$$

where $n 1$ is the proportion of the population spawning in month one, etc., and $N$ is the total number of corals in the sample.

Here, we use this SI to test the hypothesis that spawning synchrony is reduced at lower latitudes. First, we explore synchrony in these assemblages, using data from four locations where the entire Acropora assemblage was sampled for the duration of the reproductive season. The relationship between spawning synchrony and latitude is not linear as predicted by the hypothesis that increasing fluctuations in annual temperature or light cycles with latitude provide increasingly effective proximate cues for spawning synchrony. Instead, spawning synchrony peaks at mid-latitudes (central GBR), and is lower near the equator and at high latitudes (Figure $5 \boldsymbol{a}$ ). Second, we test the hypothesis that synchrony within coral populations is lower at low latitudes by plotting the SIs for four species at four locations in the Coral Sea. Once again there is no consistent pattern in
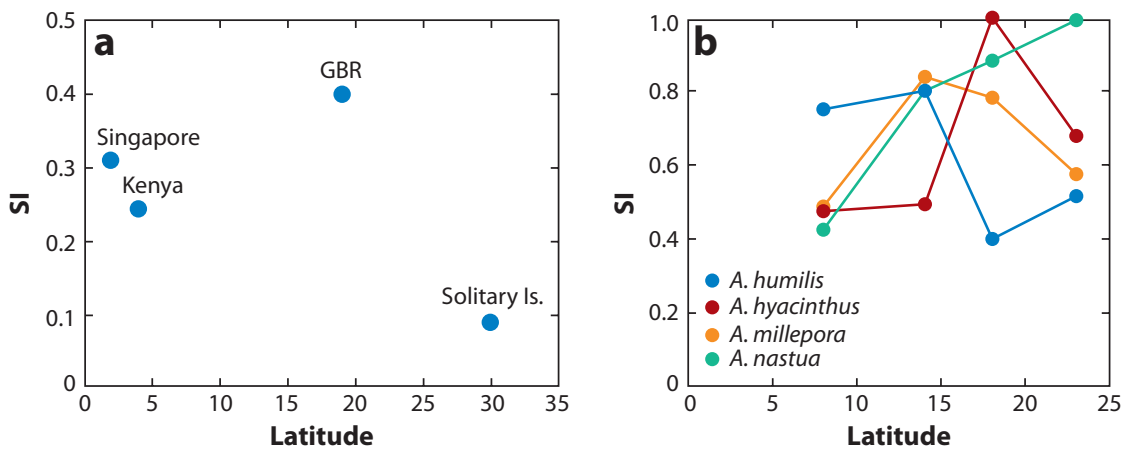

Figure 5

Spawning synchrony in Acropora as a function of latitude (a). Spawning synchrony at the assemblage level at four locations as a function of the absolute value of latitude in degrees. Data for Singapore from Guest et al. (2005a), for Kenya from Manguhbai \& Harrison (2008), for Solitary Islands from Wilson \& Harrison (2003), and for the Great Barrier Reef from this review. (b) Spawning synchrony in four Acropora species at four locations in the Coral Sea. Data from Baird et al. (2002). Sites in order of decreasing latitude are Lady Musgrave Island, Orpheus Island, Lizard Island, and Gizo in the Solomon Islands. The synchrony index (SI) is dimensionless and calculated as follows:

$$
S I=\frac{n 1(n 1-1)}{N(N-1)}+\frac{n 2(n 2-1)}{N(N-1)}+\frac{n 3(n 3-1)}{N(N-1)} \cdots,
$$

where $n 1$ is the proportion of the population spawning in month one, etc., and $N$ is the total number of corals in the sample. SI in the assemblage is the average of SI of all species examined. 
synchrony with latitude (Figure $5 \boldsymbol{b}$ ). In Acropora byacinthus and A. millepora, synchrony peaks at mid-latitudes. In $A$. nasuta, synchrony declines at lower latitudes, and in Acropora bumilis, synchrony increases at lower latitudes. Finally, we use two additional proxies for spawning synchrony: (a) the proportion of species reproductively active during the peak spawning season, and $(b)$ the number of colonies in the total assemblage breeding at the month of peak reproductive activity. The proportion of Acropora colonies breeding during peak periods was not correlated with latitude ( $\mathrm{p}=0.19 ; \mathrm{r}^{2}=10 \%$; Supplemental Appendix III), driven by the fact that at most locations within $8^{\circ}$ of the equator there are two peaks in reproductive activity (Supplemental Appendix II). Similarly, the proportion of Acropora species breeding during peak periods was not correlated with latitude ( $\mathrm{p}=0.08 ; \mathrm{r}^{2}=19 \%$; Supplemental Appendix III). Nonetheless, the minimum proportion of species breeding during the month of peak activity was $50 \%$ representing 10 species in Kenya (Supplemental Appendix III). We conclude that despite some reduction of synchrony in some species near the equator, particularly when compared to mid-latitude reefs, multispecies spawning synchrony occurs in all species-rich Acropora assemblages.

\section{Climate Change and the Reproductive Success of Scleractinian Corals}

Temperature controls the metabolic rates of all organisms, which in turn affects numerous processes within individuals, populations, and communities (O'Connor et al. 2007). A slight increase in SST can have positive effects on individuals, for example, by increasing rates of colony growth (Lough \& Barnes 2000), population growth (Edmunds et al. 2005), and larval development (O'Connor et al. 2007). However, there will always be a limit to individual tolerances, and once exceeded, any advantages associated with increased temperatures are quickly lost. In corals, the most prevalent effect of increased SST as a consequence of global warming is an increase in the scale and magnitude of mass coral bleaching events, where large numbers of susceptible individuals are killed following a breakdown in symbiosis (Carpenter et al. 2008). Deleterious effects of temperature on coral reproduction include reduced fecundity, egg quality, fertilization success, and larval survivorship (see McClanahan et al. 2009 for a review). Here, we briefly address the potential effects of changes in annual cycles of environmental variables associated with spawning synchrony and the potential effect this may have on population replenishment. In addition, we identify life-history characteristics that might make a coral species susceptible to thermal anomalies associated with climate change.

Significant changes in many biological processes as a consequence of climate change are now evident in many ecosystems (Harley et al. 2006). Indeed, shifts in phenology offer some of the best evidence for climate change-induced biological shifts (Visser 2008). Much of this research is from mid and high latitudes and from organisms for which long-term records are available, in particular plants, birds, and insects (Both et al. 2006, Visser 2008). Much less is known about shifts in phenology at lower latitudes or in marine organisms (but see Philippart et al. 2003, Edwards \& Richardson 2004). Nevertheless, changes in seasonal patterns of SST are likely to have major implications for reproductive phenology of marine organisms with highly seasonal reproduction (Olive et al. 1990). The effects of global warming on spawning synchrony in corals hinges on (a) whether sea temperature is a proximate cue or whether other climate-independent factors control reproductive timing, for example, insolation and photoperiod (see discussion above); and (b) whether corals within populations time spawning synchronously to optimize offspring survival or whether the main driver is synchrony itself, independent of the time of the year or season, for example, to satiate predators. If temperature acts as a primary cue or synergistically with other cues, then temperature changes may uncouple the phase relationship and cause a breakdown in synchrony with potentially negative consequences for fertilization success (Lawrence \& Soame 
2004). For many marine invertebrates, particularly in temperate zones, reproduction is timed to match timing of food supplies. Coral larvae are either lecithotrophic or autotrophic (see discussion above) and therefore do not feed in the water column; consequently, shifts in spawning time are unlikely to increase larval mortality through starvation. However, many broadcast spawners reproduce during intermonsoon periods when SST are close to annual maxima and when water conditions are relatively calm, suggesting that the seasonal timing of reproduction is adaptive (van Woesik et al. 2006); thus larval survival could be affected if phenology shifts increase the probability of spawning occurring during periods of inclement weather.

Glynn \& Colley (2009) propose that broadcasting species in the eastern Pacific may fare better than brooding species in the face of global warming because they possess traits that increase the probability of survival of sexual recruits and asexual fragments. Broadcast spawning species outnumber brooders in the eastern Pacific, both in terms of species richness (12 of 13 studied species are spawners) and relative abundance, potentially because they are capable of colonizing a diverse range of habitats, produce large numbers of sexual propagules that have wide dispersal potential, and tend to produce greater numbers of asexual fragments compared to brooding species. Moreover, following the mass bleaching event on the GBR in 1998, brooding species have taken longer to return to former levels of abundance than have broadcast spawning species (Emslie et al. 2008). In contrast, brooding corals now dominate many Caribbean reefs following disturbances in the 1980s and 1990s (Knowlton 2001), and their recruits outnumber those of spawners following mass bleaching events (McField 1999).

In summary, although the effects of repeated mass bleaching events are likely to be profound in terms of causing widespread mortality of coral assemblages, climate change is also likely to significantly affect coral reproductive success and phenology and thus the very processes required to replenish reefs following bleaching disturbances. More detailed information on the seasonal timing of spawning and synchrony within populations is urgently required as a baseline against which to test the effects of climate change.

\section{SUMMARY POINTS}

1. Previous hypotheses on systematic patterns in coral reproduction, including the highly conserved nature of coral sexuality and the relatively plastic nature of mode of larval development, have been verified by analyses of substantially increased data on coral reproductive biology in the context of a new molecular phylogeny and by recent phylogenetic analyses of the evolution of these traits.

2. Scleractinian fauna in the western Atlantic has a substantial overabundance of corals that brood larvae. We hypothesize that this pattern is the result of differences in the dispersal ability of brooded larvae that are, almost without exception, autotrophic and therefore have a greater capacity for long-distance dispersal than have lecithotrophic larvae.

3. Fauna in the eastern Pacific is dominated by species with autotrophic larvae, supporting the idea that dispersal from the central Pacific is responsible for the unique nature of this fauna.

4. Multispecies spawning events occur in all speciose coral assemblages globally. Lower spawning synchrony in many coral species and coral assemblages near the equator, in comparison to mid-latitude reefs, typically reflects two distinct peaks in reproductive activity near the equator. 
5. Corals rely on a number of environmental cues, potentially including seasonal temperature patterns, to synchronize spawning, although more research is required to unequivocally identify these cues. Reliance on external cues suggests that climate-induced changes in environmental cues have the potential to disrupt spawning synchrony, and thereby reduce the resilience of reef ecosystems.

\section{DISCLOSURE STATEMENT}

The authors are not aware of any affiliations, memberships, funding, or financial holdings that might be perceived as affecting the objectivity of this review.

\section{ACKNOWLEDGMENTS}

We thank Y. Loya, P. Todd, and R. Van Woesik for valuable comments on an earlier version of this manuscript and A. Kerr for producing Figure 2. We thank P. Aliño, D. Ayre, R. Babcock, D. Bathelemy, E. Borneman, S. Brooke, S. Cairns, A. Chen, M. Coffroth, S. Colley, F. Cox, C. Delbeek, L. Delvoye, T. Fan, M. Fine, P. Fiene-Severns, Y. Golbuu, S. Harii, G. Hodson, C. Hunter, D. Levitan, Y. Loya, A. Marshall, S. Mangubhai, A. Morse, C. Mundy, L. Penland, D. Petersen, U. Phyllia, J. Pinzon, D. Pires, D. Ploria, A. Szmant, A. Stroides, P. Glynn, Y. Nakano, K. Sakai, B. Segal, M. Vermeij, S. Vollmer, R. Waller, E. Weil, and J. Wolstenholme for contributing unpublished data and advice.

\section{LITERATURE CITED}

Ayre DJ, Miller KJ. 2004. Where do clonal coral larvae go? Adult genotypic diversity conflicts with reproductive effort in the brooding coral Pocillopora damicornis. Mar. Ecol. Prog. Ser. 277:95-105

Babcock RC, Bull GD, Harrison PL, Heyward AJ, Oliver JK, et al. 1986. Synchronous spawnings of 105 scleractinian coral species on the Great Barrier Reef. Mar. Biol. 90:379-94

Babcock RC, Willis BL, Simpson CJ. 1994. Mass spawning of corals on a high-latitude coral-reef. Coral Reefs 13:161-69

Baird AH, Guest JR. 2009. Spawning synchrony in scleractinian corals: comment on Mangubhai \& Harrison (2008). Mar: Ecol. Prog. Ser. 374:301-4

Baird AH, Marshall PA, Wolstenholme J. 2002. Latitudinal variation in the reproduction of Acropora in the Coral Sea. Proc. 9th Int. Coral Reef. Symp. I:385-9

Barrett SCH. 1998. The evolution of mating strategies in flowering plants. Trends Ecol. Evol. 3:335-41

Both C, Bouwhuis S, Lessells CM, Visser ME. 2006. Climate change and population declines in a long-distance migratory bird. Nature 441:81-83

Cairns SD. 1988. Asexual reproduction in solitary Scleractinia. Proc. 6th Int. Coral Reef. Symp. 10:641-46

Cairns SD. 1999. Species richness of recent Scleractinia. Atoll Res. Bull. 459:1-46

Carlon DB. 1999. The evolution of mating systems in tropical reef corals. Trends Ecol. Evol. 14:491-95

Carpenter KE, Abrar M, Aeby G, Aronson RB, Banks S, et al. 2008. One-third of reef-building corals face elevated extinction risk from climate change and local impacts. Science 321:560-63

Charnov EL. 1982. The Theory of Sex Allocation. New York: Princeton Univ. Press

Daly M, Fautin DG, Cappola VA. 2003. Systematics of the Hexacorallia (Cnidaria: Anthozoa). Zool. F. Linn. Soc. 139:419-37

Delvoye L. 1988. Gametogenesis and gametogenic cycles in Agaricia agaricites (L) and Agaricia humilis Verrill and notes on gametogenesis in Madracis mirabilis (Duchassaing \& Michelotti) (Scleractinia). Uitgaven. Nat. Stud. Suriname Ned. Antillen 123:101-34 
Diekmann OE, Bak RPM, Tonk L, Stam WT, Olsen JL. 2002. No habitat correlation of zooxanthellae in the coral genus Madracis on a Curacao reef. Mar. Ecol. Prog. Ser. 227:221-32

Duerden JE. 1902. West Indian madreporarian polyps. Mem. Natl. Acad. Sci. 8:403-648

Edinger EN, Risk MJ. 1995. Preferential survivorship of brooding corals in a regional extinction. Paleobiology 21:200-19

Edmunds PJ, Gates RD, Leggat W, Hoegh-Guldberg O, Allen-Requa L. 2005. The effect of temperature on the size and population density of dinoflagellates in larvae of the reef coral Porites astreoides. Invertebr. Biol. 124:185-93

Edwards M, Richardson AJ. 2004. Impact of climate change on marine pelagic phenology and trophic mismatch. Nature 430:881-84

Emslie MJ, Cheal AJ, Sweatman H, Delean S. 2008. Recovery from disturbance of coral and reef fish communities on the Great Barrier Reef, Australia. Mar. Ecol. Prog. Ser. 371:177-90

Fautin DG. 2002. Reproduction of Cnidaria. Can. 7. Zool. 80:1735-54

Francis RC. 1992. Sexual lability in teleosts: developmental factors. Q. Rev. Biol. 67:1-18

Fukami H, Budd AF, Paulay G, Sole-Cava A, Chen CLA, et al. 2004. Conventional taxonomy obscures deep divergence between Pacific and Atlantic corals. Nature 427:832-35

Fukami H, Chen CA, Budd AF, Collins A, Wallace C, et al. 2008. Mitochondrial and Nuclear Genes Suggest that Stony Corals Are Monophyletic but Most Families of Stony Corals Are Not (Order Scleractinia, Class Anthozoa, Phylum Cnidaria). PLoS ONE 3:e3222

Giese AC, Pearse JS. 1974. Introduction: general principles. In Reproduction of Marine Invertebrates. I Acoelomate and Pseudocoelomate Metazoans, ed. AC Giese, JS Pearse, pp. 1-49. New York: Academic

Glynn PW, Ault JS. 2000. A biogeographic analysis and review of the far eastern Pacific coral reef region. Coral Reefs 19:1-23

Glynn PW, Colley NJ. 2009. Survival of brooding and broadcasting reef corals following large scale disturbances: Is there any hope for broadcasting species during global warming. Proc. Int. Coral Reef Symp., 11th, Fort Lauderdale, Florida. In press

Glynn PW, Colley SB, Eakin CM, Smith DB, Cortes J, et al. 1994. Reef coral reproduction in the eastern Pacific: Costa Rica, Panama, and Galapagos Islands (Ecuador). 2. Poritidae. Mar. Biol. 118:191-208

Glynn PW, Colley SB, Gassman NJ, Black K, Cortes J, Mate JL. 1996. Reef coral reproduction in the eastern Pacific: Costa Rica, Panama, and Galapagos Islands (Ecuador). 3. Agariciidae (Pavona gigantea and Gardineroseris planulata). Mar. Biol. 125:579-601

Gorbunov MY, Falkowski PG. 2002. Photoreceptors in the cnidarian hosts allow symbiotic corals to sense blue moonlight. Limnol. Oceanogr. 47:309-15

Graham ER, Baird AH, Connolly SR. 2008. Survival dynamics of scleractinian coral larvae and implications for dispersal. Coral Reefs 27:529-39

Guest JR, Baird AH, Goh BPL, Chou LM. 2005a. Reproductive seasonality in an equatorial assemblage of scleractinian corals. Coral Reefs 24:112-16

Guest JR, Baird AH, Goh BPL, Chou LM. 2005b. Seasonal reproduction in equatorial reef corals. Invertebr. Reprod. Dev. 48:207-18

Harley CDG, Randall Hughes A, Hultgren KM, Miner BG, Sorte CJB, et al. 2006. The impacts of climate change in coastal marine systems. Ecol. Lett. 9:228-41

Harrison PL. 1988. Pseudo-gynodioecy: an unusual breeding system in the scleractinian coral Galaxea fascicularis. Proc. 6th. Int. Coral Reef Symp. 2:699-705

Harrison PL. 1990. Sperm morphology and fertilization strategies in scleractinian corals. Adv. Invertebr. Reprod. 5:299-304

Harrison PL, Babcock RC, Bull GD, Oliver JK, Wallace CC, Willis BL. 1984. Mass spawning in tropical reef corals. Science 223:1187-88

Harrison PL, Booth DJ. 2007. Coral Reefs: Naturally dynamic and increasingly disturbed ecosystems. In Marine Ecology, ed. SD Connell, BM Gillanders, pp. 316-77. London: Oxford Univ. Press

Harrison PL, Wallace CC. 1990. Reproduction, dispersal and recruitment of scleractinian corals. In Coral Reefs, ed. Z Dubinsky, pp. 133-207. Amsterdam: Elsevier 
Huang DW, Meier R, Todd PA, Chou LM. 2009. More evidence for pervasive paraphyly in scleractinian corals: systematic study of Southeast Asian Faviidae (Cnidaria; Scleractinia) based on molecular and morphological data. Mol. Phylogenet. Evol. 50:102-16

Hughes TP, Baird AH, Dinsdale EA, Moltschaniwskyj NA, Pratchett MS, et al. 2000. Supply-side ecology works both ways: the link between benthic adults, fecundity, and larval recruits. Ecology 81:2241-9

Hunter CL. 1988. Environmental cues controlling spawning in two Hawaiian corals, Montipora verrucosa and M. dilitata. Proc. 6th. Int. Coral Reef. Symp. 2:727-32

Johnson KG, Budd AF, Stemann TA. 1995. Extinction selectivity and ecology of neogene Caribbean reef corals. Paleobiology 21:52-73

Jokiel PL, Ito RY, Liu PM. 1985. Night irradiance and synchronization of lunar release of panula larvae in the reef coral Pocillopora damicornis. Mar. Biol. 88:167-74

Kenyon JC. 2008. Acropora (Anthozoa: Scleractinia) reproductive synchrony and spawning phenology in the northern Line Islands, Central Pacific, as inferred from size classes of developing oocytes. Pac. Sci. 62:569_ 78

Kerr AM. 2005. Molecular and morphological supertree of stony corals (Anthozoa: Scleractinia) using Matrix Representation Parsimony. Biol. Rev. 80:543-58

Kinzie RA. 1993. Spawning in the reef corals Pocillopora verrucosa and P. eydouxi at Sesoko Island, Okinawa. Galaxea 11:93-105

Knowlton N. 2001. The future of coral reefs. Proc. Natl. Acad. Sci. USA 98:5419-25

Kramarsky-Winter E, Loya Y. 1998. Reproductive strategies of two fungiid corals from the northern Red Sea: environmental constraints? Mar. Ecol. Prog. Ser. 174:175-82

Lawrence AJ, Soame JM. 2004. The effects of climate change on the reproduction of coastal invertebrates. Ibis 146:29-39

Levitan DR, Fukami H, Jara J, Kline D, McGovern TM, et al. 2004. Mechanisms of reproductive isolation among sympatric broadcast-spawning corals of the Montastraea annularis species complex. Evolution 58:308-23

Levy O, Appelbaum L, Leggat W, GothlifY, Hayward DC, et al. 2007. Light-responsive cryptochromes from a simple multicellular animal, the coral Acropora millepora. Science 318:467-70

Lough JM, Barnes DJ. 2000. Environmental controls on growth of the massive coral Porites. F. Exp. Mar. Biol. Ecol. 245:225-43

Loya Y, Sakai K. 2008. Bidirectional sex change in mushroom stony corals. Proc. R. Soc. Ser. B 275:2335-43

Mangubhai S, Harrison PL. 2008a. Asynchronous coral spawning patterns on equatorial reefs in Kenya. Mar. Ecol. Prog. Ser. 360:85-96

Mangubhai S, Harrison PL. 2008b. Gametogenesis, spawning and fecundity of Platygyra daedalea (Scleractinia) on equatorial reefs in Kenya. Coral Reefs 27:117-22

McClanahan T, Weil E, Cortés J, Baird AH, Ateweberhan M. 2009. Consequences of coral bleaching for sessile reef organisms. In Ecological Studies: Coral Bleaching: Patterns, Processes, Causes and Consequences, ed. MJH van Oppen, JM Lough, pp. 121-38. Berlin: Springer-Verlag

McFadden CS, Donahue R, Hadland BK, Weston R. 2001. A molecular phylogenetic analysis of reproductive trait evolution in the soft coral genus Alcyonium. Evolution 55:54-67

McField MD. 1999. Coral response during and after mass bleaching in Belize. Bull. Mar. Sci. 64:155-72

Mendes JM, Woodley JD. 2002. Effect of the 1995-1996 bleaching event on polyp tissue depth, growth, reproduction and skeletal band formation in Montastraea annularis. Mar. Ecol. Prog. Ser. 235:93-102

Morse ANC, Iwao K, Baba M, Shimoike K, Hayashibara T, Omori M. 1996. An ancient chemosensory mechanism brings new life to coral reefs. Biol. Bull. 191:149-54

O'Connor MI, Bruno JF, Gaines SD, Halpern BS, Lester SE, et al. 2007. Temperature control of larval dispersal and the implications for marine ecology, evolution, and conservation. Proc. Natl. Acad. Sci. USA 104:1266-71

Olive PW, Clark S, Lawrence A. 1990. Global warming and seasonal reproduction: perception and transduction of environmental information. Adv. Invert. Repro. 5: 265-70

Olive PJW, Lewis C, Beardall V. 2000. Fitness components of seasonal reproduction: an analysis using Nereis virens as a life history model. Oceanol. Acta 23:377-89 
Oliver J, Babcock RC. 1992. Aspects of the fertilization ecology of broadcast spawning corals: sperm dilution effects and in situ measurements of fertilization. Biol. Bull. Mar. Biol. Lab. Woods Hole 183:409-17

Oliver JK, Babcock RC, Harrison PL, Willis BL. 1988. Geographic extent of mass coral spawning: clues to ultimate causal factors. Proc. 6th. Int. Coral Reef Symp. 2:803-10

Pechenik. 1990. Delayed metamorphosis by larvae of benthic marine invertebrates: Does it occur? Is there a price to pay? Ophelia 32:63-94

Penland L, Kloulechad J, Idip D, van Woesik R. 2004. Coral spawning in the western Pacific Ocean is related to solar insolation: evidence of multiple spawning events in Palau. Coral Reefs 23:133-40

Philippart CJM, van Aken HM, Beukema JJ, Bos OG, Cadee GC, Dekker R. 2003. Climate-related changes in recruitment of the bivalve Macoma balthica. Limnol. Oceanogr: 48:2171-85

Plathong S, Chanmethakul T, Suwonno V, Buaphet P, Baird AH, et al. 2006. Daytime gamete release from the reef-building coral, Pavona sp., in the Gulf of Thailand. Coral Reefs 25:72

Richmond RH. 1988. Competency and dispersal potential of planula larvae of a spawning versus a brooding coral. Proc. 6th. Int. Coral Reef Symp. 2:827-31

Richmond RH, Hunter CL. 1990. Reproduction and recruitment of corals: comparisons among the Caribbean, the Tropical Pacific, and the Red Sea. Mar. Ecol. Prog. Ser. 60:185-203

Rinkevich B, Loya Y. 1979. Reproduction of the Red-Sea coral Stylophora pistillata 2. Synchronization in breeding and seasonality of planulae shedding. Mar. Ecol. Prog. Ser. 1:145-52

Romano SL, Cairns SD. 2000. Molecular phylogenetic hypotheses for the evolution of scleractinian corals. Bull. Mar. Sci. 67:1043-68

Rosser NL, Baird AH. 2009. Multi-specific coral spawning in spring and autumn in far north-western Australia. Proc. Int. Coral Reef Symp., 11th, Fort Lauderdale, Florida. In press

Shlesinger Y, Loya Y. 1985. Coral community reproductive patterns: Red Sea versus the Great Barrier Reef. Science 228:1333-35

Simpson CJ. 1985. Mass spawning of scleractinian corals in the Dampier Archipelago and the implications for management of coral reefs in Western Australia. Rep. 244, Dep. Conserv. Environ. West. Aust. Bull., Perth

Soong K. 1991. Sexual reproductive patterns of shallow-water reef corals in Panama. Bull. Mar. Sci. 49:832-46

Stobart B, Babcock RC, Willis BL. 1993. Biannual spawning of three species of scleractinian coral from the Great Barrier Reef. Proc. 7th. Int. Coral Reef. Symp. 1:494-99

Stoddart JA. 1983. Asexual production of planulae in the coral Pocillopora damicornis. Mar. Biol. 76:279-84

Szmant AM. 1986. Reproductive ecology of Caribbean reef corals. Coral Reefs 5:43-54

van Woesik R, Lacharmoise F, Koksal S. 2006. Annual cycles of solar insolation predict spawning times of Caribbean corals. Ecol. Lett. 9:390-98

Veron JEN. 1995. Corals in Space and Time. Sydney: Southwood Press. 321 pp.

Veron JEN. 2000. Corals of the World. Townsville: AIMS

Veron JEN, Odorico DM, Chen CA, Miller DJ. 1996. Reassessing evolutionary relationships of scleractinian corals. Coral Reefs 15:1-9

Visser ME. 2008. Keeping up with a warming world; assessing the rate of adaptation to climate change. Proc. R. Soc. Ser. B 275:649-59

Vize PD. 2006. Deepwater broadcast spawning by Montastraea cavernosa, Montastraea franksi, and Diploria strigosa at the Flower Garden Banks, Gulf of Mexico. Coral Reefs 25:169-71

Weiblen GD, Oyama RK, Donoghue MJ. 2000. Phylogenetic analysis of dioecy in monocotyledons. Am. Nat. 155:46-58

Wells JW. 1957. Annotated bibliography of marine ecology_corals. In Treatise on Marine Ecology and Paleoecology, Mem. Geol. Soc. Am. 67, ed. JW Hedgepeth. 1:1087-104

Willis BL, Babcock RC, Harrison PL, Oliver JK. 1985. Patterns in the mass spawning of corals on the Great Barrier Reef from 1981 to 1984. Proc. 5th. Int. Coral Reef Symp. 4:343-48

Wilson JR, Harrison PL. 2003. Spawning patterns of scleractinian corals at the Solitary Islands—a high latitude coral community in eastern Australia. Mar. Ecol. Prog. Ser. 260:115-23

Wolstenholme JK. 2004. Temporal reproductive isolation and gametic compatibility are evolutionary mechanisms in the Acropora bumilis species group (Cnidaria; Scleractinia). Mar. Biol. 144:567-82

Yakovleva I, Baird AH, Yamamoto HH, Bhagooli R, Nonaka M, Hidaka M. 2009. Algal symbionts increase oxidative damage and death in coral larvae at high temperature. Mar. Ecol. Prog. Ser. 378:105-12 
Associational Resistance and Associational Susceptibility: Having Right or Wrong Neighbors

Pedro Barbosa, Fessica Hines, Ian Kaplan, Holly Martinson, Adrianna Szczepaniec, and Zsofia Szendrei

The Importance of Ecological and Phylogenetic Conditions for the

Occurrence and Frequency of Sexual Cannibalism

Shawn M. Wilder, Ann L. Rypstra, and Mark A. Elgar

Abundant Genetic Variation + Strong Selection $=$ Multivariate

Genetic Constraints: A Geometric View of Adaptation

Bruce Walsh and Mark W. Blows

Responses of Humid Tropical Trees to Rising $\mathrm{CO}_{2}$

Christian Körner

The Role of Propagule Pressure in Biological Invasions

Daniel Simberloff.

Nongenetic Inheritance and Its Evolutionary Implications

Russell Bonduriansky and Troy Day....

The Ecology and Evolution of Microbes that Manipulate

Host Reproduction

Fan Engelstädter and Gregory D.D. Hurst

Spontaneous Mutation Accumulation Studies in Evolutionary Genetics

Daniel L. Halligan and Peter D. Keightley

Geologic and Biologic Controls on the Evolution of Reefs

Wolfgang Kiessling

Molecular Estimation of Dispersal for Ecology and Population Genetics

Thomas Broquet and Eric 7. Petit

Flower Evolution: The Origin and Subsequent Diversification of the Angiosperm Flower Chelsea D. Specht and Madelaine E. Bartlett 
Is There a Latitudinal Gradient in the Importance of Biotic Interactions?

Douglas W. Schemske, Gary G. Mittelbach, Howard V. Cornell, Fames M. Sobel, and Kaustuv Roy

Evolution of Placentas in the Fish Family Poeciliidae: An Empirical

Study of Macroevolution

B.7.A. Pollux, M.N. Pires, A.I. Banet, and D.N. Reznick

Gene Flow and Isolation among Populations of Marine Animals

Michael E. Hellberg.

Latex: A Model for Understanding Mechanisms, Ecology, and

Evolution of Plant Defense Against Herbivory

Anurag A. Agrawal and Kotaro Konno

What Salamanders Have Taught Us About Evolution

David B. Wake

The Evolutionary Genetics of Emerging Viruses

Edward C. Holmes

Belowground Herbivory and Plant Defenses

Nicole M. van Dam

The Causes and Consequences of Compensatory Dynamics

in Ecological Communities

Andrew Gonzalez and Michel Loreau

Evolution and Ecology of Species Range Limits

Fason P. Sexton, Patrick 7. McIntyre, Amy L. Angert, and Kevin F. Rice

Woody Plant Diversity, Evolution, and Ecology in the Tropics:

Perspectives from Seasonally Dry Tropical Forests

R. Toby Pennington, Matt Lavin, and Ary Oliveira-Filho

Comparative Genomics on the Drosophila Phylogenetic Tree

Nadia D. Singh, Amanda M. Larracuente, Timothy B. Sackton,

and Andrew G. Clark

Genetic Consequences of Range Expansions

Laurent Excoffier, Matthieu Foll, and Rémy 7. Petit ....

Stoichiometrically Explicit Food Webs: Feedbacks between Resource

Supply, Elemental Constraints, and Species Diversity

Spencer R. Hall

Changing Ecology of Tropical Forests: Evidence and Drivers

Simon L. Lewis, Fon Lloyd, Stephen Sitch, Edward T.A. Mitchard,

and William F. Laurance 
Systematic and Biogeographical Patterns in the Reproductive Biology of Scleractinian Corals Andrew H. Baird, Fames R. Guest, and Bette L. Willis

Effects of Natural Enemy Biodiversity on the Suppression of Arthropod Herbivores in Terrestrial Ecosystems Deborab K. Letourneau, Fulie A. Fedlicka, Sara G. Botbwell, and Carlo R. Moreno ... 573

Statistical Phylogeography

L. Lacey Knowles

The Nitrogen Paradox in Tropical Forest Ecosystems

Lars O. Hedin, E.N. Jack Brookshire, Duncan N.L. Menge, and Alexander R. Barron

The Role of Animal Pollination in Plant Speciation:

Integrating Ecology, Geography, and Genetics Katbleen M. Kay and Risa D. Sargent

Rates of Evolution

Philip D. Gingerich

Species Distribution Models: Ecological Explanation and Prediction Across Space and Time Jane Elith and Fohn R. Leathwick

Mycorrhizal Symbioses and Plant Invasions Anne Pringle, Fames D. Bever, Monique Gardes, Feri L. Parrent, Matthias C. Rillig, and Fobn N. Klironomos

\section{Indexes}

Cumulative Index of Contributing Authors, Volumes 36-40

Cumulative Index of Chapter Titles, Volumes 36-40

\section{Errata}

An online log of corrections to Annual Review of Ecology, Evolution, and Systematics articles may be found at http://ecolsys.annualreviews.org/errata.shtml 